\title{
Low Velocity Impact and Tensile Performance of GFRPs Interleaved with Electrospun Nylon 6,6 Nanofiber Mats
}

\author{
Murat YILDIZ*, Ahmet YAPICI, Vildan ÖZKAN, Ömer Sinan ŞAHIN
}

\begin{abstract}
Nanofibers can be interleaved into polymers and improvements in mechanical properties such as resistance to impact, delamination and debonding as well as enhanced ductility can be obtained. In this work, GFRP laminated composites were interleaved to non-woven nylon 6,6 nanofiber mats which were generated by the electrospinning method. Four kinds of configurations were considered; two pure configurations where GFRP had two and four glass fiber layers and the other two kinds of nanofiber modified configurations that had one and three nylon 6,6 nanofiber mats being interleaved in GFRP. Those specimens were then investigated for their impact resistance, energy absorption and tensile strength capabilities in regard to low-velocity impact and tensile tests. The results showed that adding nylon 6,6 nanofiber mats can increase energy absorption values of the modified specimens, but some decrease in load capacities could be observed.
\end{abstract}

Keywords: electrospinning; GFRP; low velocity impact; nylon 6,6; tensile test

\section{INTRODUCTION}

Glass Fiber Reinforced Polymer (GFRP) is a lightweight and durable material that can be used in many areas. During manufacturing, physical disunities and mismatches can lead to problems such as the increased delaminations. Thus when composites are exposed to external forces, even a weak blow may damage a composite enough to cause a critical fracture and render it useless. To minimize this problem, interleaving nanofiber mats in the composites can be utilized [1-4]. Electrospinning can be said to be one of the most frequently used methods to generate nanofiber mats in recent years $[5,6]$. Nylon 6,6 is a thermoplastic polyamide and due to its good mechanic properties [7] it is frequently used as the raw material for generating nanofibers.

In literature, many studies inspected mechanical performances of pure GFRP [8-11], the nanofiber modified GFRP composites [3, 12, 13]. Namely, in their study, Saghafi et al. [2] tried to examine the effect of electrospun nanofibers on GFRP laminated composites by adding nanofiber mats into their composite materials and found that the energy release rates of the composite materials modified with nylon 6,6 nanofiber mats achieved $62 \%$ and $109 \%$ gains for $\mathrm{G}_{\mathrm{IC}}$ and $\mathrm{G}_{\mathrm{IIC}}$, respectively. Brugo et al. [14] also electrospun nylon 6,6 nanofiber mats and then added those mats into CFRP as reinforcing the material. They found out that crack propagation was slower than the pure CFRP by up to 36 times. An increase in delamination toughness by $130 \%$ was also observed. Beylergil et al., [15] interleaved nylon 6,6 non-woven mats into CFRP composites and found out that composites, when interleaved with the mats, showed improvements of about $350 \%$ at the initiation and $720 \%$ at the propagation of fracture toughness. However, compromises in tensile tests occurred due to the reduced amount of carbon fiber in the specimens and an increase in thickness. They also noted that for Mode-I fracture toughness, nylon would be the material that is most effective for interleaving.

The studies show that nanofiber mats might provide considerable improvements to laminated composites. Therefore, in our study, nylon 6,6 nanofiber mats were electrospun and then interleaved into glass fiber/epoxy to manufacture nanofiber modified GFRP composites in two different configurations and two kinds of pure GFRP specimens were prepared as well. Low velocity impact tests and tensile tests were conducted on the specimens. Comparisons were made to investigate the effects of the nanofiber mats on impact resistance, energy absorption and tensile strength capabilities of the specimens.

\section{MATERIAL AND METHOD \\ 2.1 Manufacturing nanofiber mats}

For manufacturing, nanofiber mats were generated by using the electrospinning method. The nylon 6,6 granules were supplied from Sigma Aldrich [16]. The granules were dissolved in a mix of two different acids; $99-100 \%$ pure Formic Acid and 99,9\% Dichloromethane in a concentration of $10 \% \mathrm{w} / \mathrm{w}$. The acids were put together in $1: 1 v / v$ ratio. The solution was put in an ultrasonic bath device for about 8 hours, at room temperature to obtain as homogenous disposition as possible. The final solution can be seen in Fig. 1a.

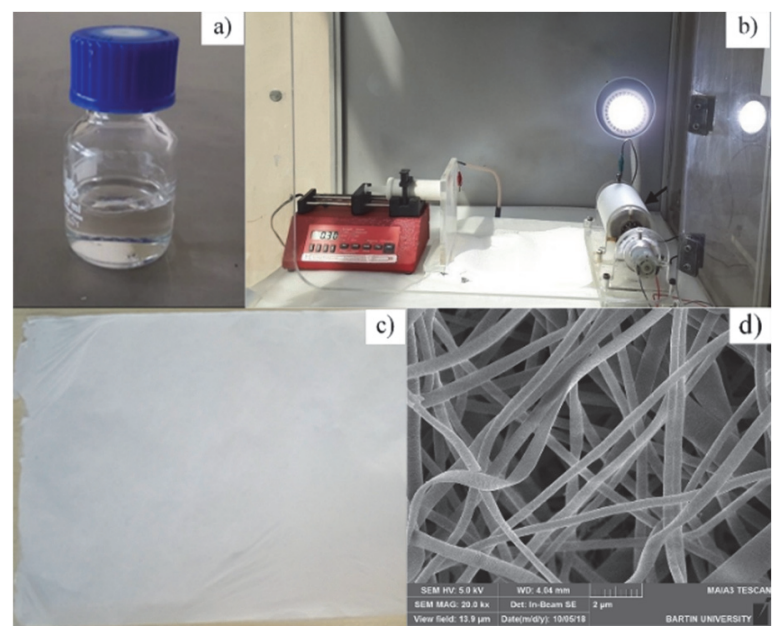

Figure 1 Electrospinning process and obtained nanofiber mats: a) prepared solution; b) electrospinning device; c) nanofiber mat; d) SEM image of the nanofibers

The solution was drawn into a $10 \mathrm{ml}$ syringe and then placed into a syringe pump system. The electrospinning process was performed in the following conditions: voltage 
$30 \mathrm{kV}$, distance between the cylindrical collector and the needle $200 \mathrm{~mm}$, feed rate $0,65 \mathrm{ml} / \mathrm{h}$, drum speed $70 \mathrm{rpm}$, temperature $25{ }^{\circ} \mathrm{C}$, relative humidity $50-60 \%$ and the process continued until the syringe was empty. The components of the electrospinning device can be seen in Fig. 1b.

The electrospun nanofiber mats were left at room temperature for about 72 hours to evaporate solvents. The mats had about 3,2 $\pm 0,3 \mu \mathrm{m}$ of thickness and 17,2 $\pm 0,3$ $\mathrm{g} / \mathrm{m}^{2}$ of areal density. The electrospun mats and the SEM image of the nanofibers are given in Fig. 1c and Fig. 1d, respectively.

The fibers varied in diameter and continuity. The diameters of the nanofibers were determined by using ImageJ software and the mean values were $400 \pm 0,07 \mathrm{~nm}$.

\subsection{Preparing Laminate Composites}

Hexion branded epoxy code named H160 was used [17] as matrix. The resin and the hardener were mixed in a weight ratio of $80 \%$ and $20 \%$, respectively. Dry E-Glass fiber layers were cut in $150 \times 100 \mathrm{~mm}^{2}$ proportions, and the orientations were $\left[0^{\circ} / 90^{\circ}\right]$. The glass fibers had 2,94 \pm $0,1 \mathrm{~g} / \mathrm{mm}^{2}$ areal density, $2 \times 10^{-5} \mathrm{~kg} / \mathrm{cm}^{2}$ tensile strength and $0,2 \mathrm{~mm}$ thickness.

Four kinds of configurations for the specimens were considered. Two kinds of pure GFRP composites that included two and four glass fiber layers are depicted in Fig. $2 \mathrm{a}$ and Fig. $2 \mathrm{~b}$ respectively. Two kinds of nanofiber modified GFRP composites that were one and three nanofiber mats were interleaved into two glass fiber layered GFRP and depicted in Fig. 2c and Fig. 2d respectively.

The specimens were manufactured according to ASTM D7136 for low velocity impact and ASTM D638 for tensile tests. They were manufactured by the hand layup method where the iron molds were used as well.

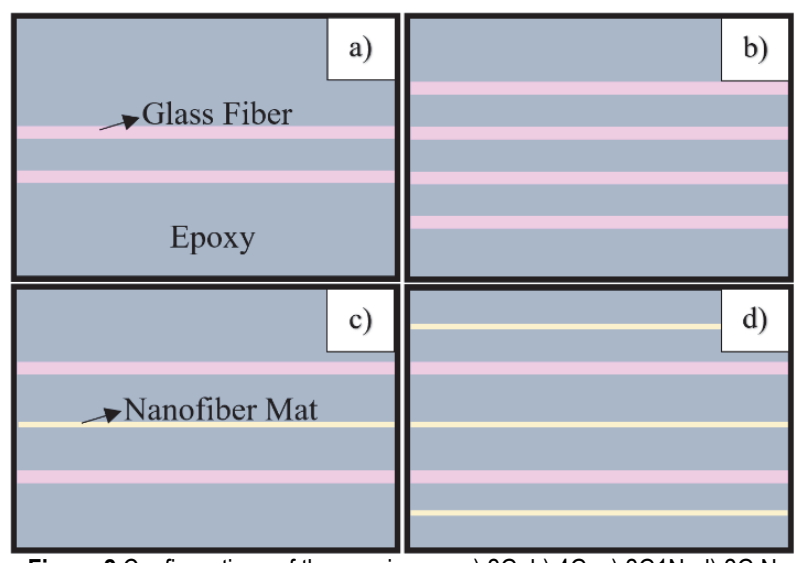

Figure 2 Configurations of the specimens: a) 2G; b) 4G; c) $2 \mathrm{G} 1 \mathrm{~N}$; d) $2 \mathrm{G} \mathrm{N}$

The specimens were left in place with room conditions for 24 hours and then removed from the mold afterwards. For the tests, three specimens for each of the four groups were manufactured.

\subsection{Conducting Low Velocity Impact Tests}

Low velocity tests were conducted on the specimens according to ASTM D7136. The structure of the device was a drop tower in which existed an impactor that had a hemispherical tip with a diameter of $12 \mathrm{~mm}$ and a mass of $5,6 \mathrm{~kg}$. The specimens were centered into a rigid steel rectangular fixture, and four clamps were deployed to make sure the specimens stayed still. After fixation, the impactor would move at a velocity of $1,5 \mathrm{~m} / \mathrm{s}$ thus gaining impact energy equal to $6,3 \mathrm{~J}$. The force signals were captured by using a millivolt force sensor. A signal processor amplified and filtered the signals and they were gathered at a data acquisition card. NI Signal Express ${ }^{\circledR}$ software was used to examine the force changes that took place when impactor hit the specimen. The sampling rate of the data acquisition system was $25 \mathrm{kHz}$. Velocity and displacement of the impactor were calculated by referring to Newton's second law of motion while error corrections were considered. Usually, until the energy is entirely consumed, the impactor would hit the specimens 12-15 times due to rebounding effect. To prevent this problem, the device had an anti-rebounding system and this made it possible to investigate the effects of just one impact. In Fig. $3 \mathrm{a}$ the device can be observed.

\subsection{Conducting Tensile Tests}

Tensile tests were conducted according to ASTM D638 and carried out using a tensile testing device named TIRA test 24500. The device is suitable for the tensile tests of low and high strength materials. The crosshead speed was set to $1 \mathrm{~mm} / \mathrm{min}$. Displacement values were obtained with motion sensors. The data obtained during the tests were transferred to a computer. With the help of the analysis software of the device, stress-strain graphs were obtained from the values. In Fig. $3 b$ the test device with a specimen processed can be seen.

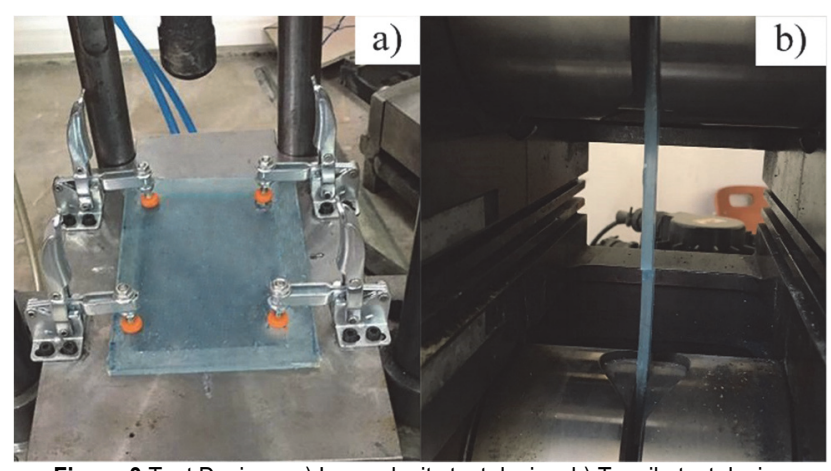

Figure 3 Test Devices: a) Low velocity test device; b) Tensile test device

\section{RESULTS AND DISCUSSION 3.1 Low velocity tests}

During low velocity impact tests, the energy consumed in the force sensor was not considered. The energy consumed in these apparatuses, as well as the friction losses in the system during movements, were also neglected. When these omissions are taken into account, it can be assumed that the sum of the energy absorbed by the specimens and the repulsive energy of the impactor can give the total energy. The absorbed energy is used in shape alterations and damage mechanisms in the specimens. Force-time, force-displacement, energy-time, energydisplacement and impulse graphs were prepared and interpreted by using the data obtained by the tests. 
Specimen groups were compared among themselves and the optimum specimens which had the medium values of their group were selected as representatives. Comparisons of these representatives are given below. In the figures, $2 \mathrm{G}$ represents pure GFRP specimens with two glass fiber layers, 4G represents pure GFRP specimens
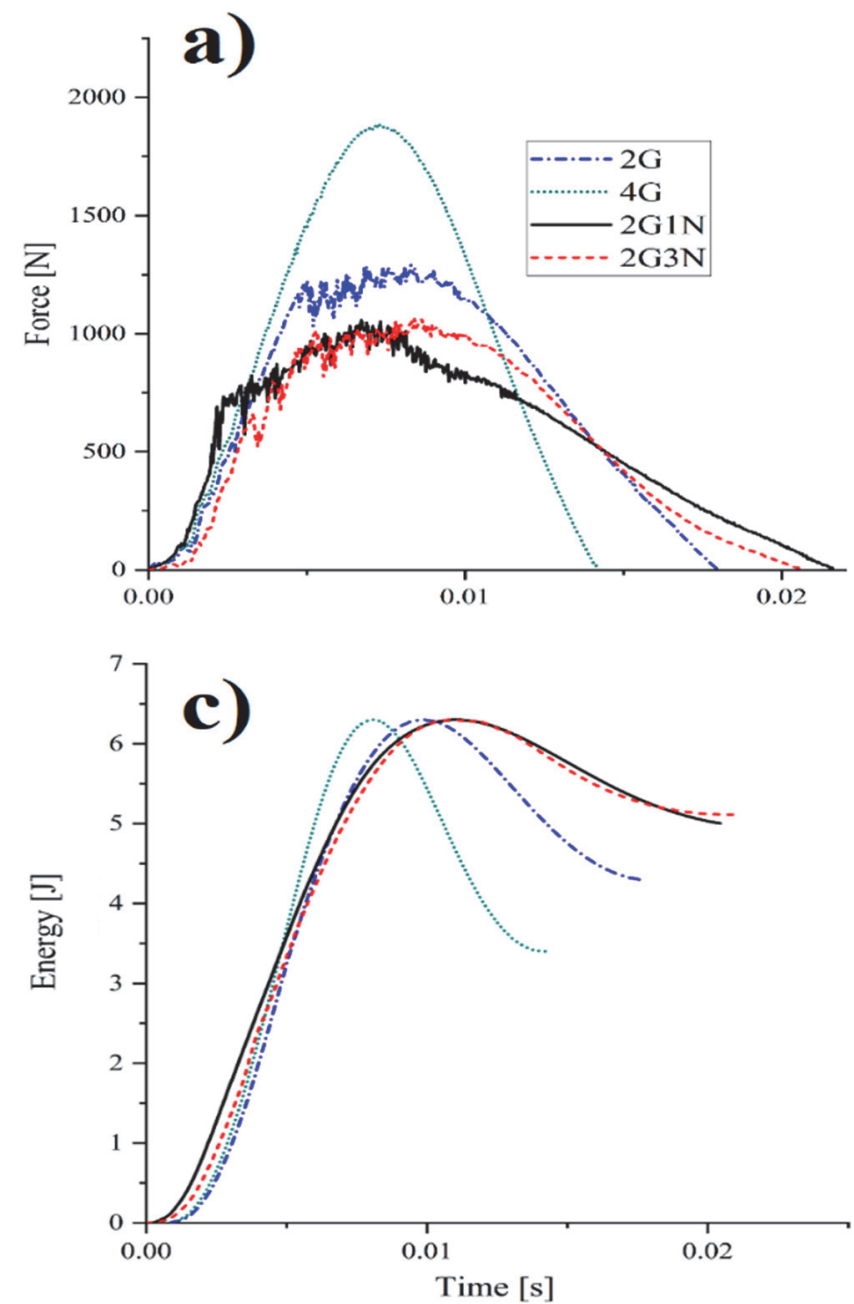

Figure 4 a) Force-time graph; b) Force-displacement graph; c) Energy-time graph; d) Energy-displacement graph

It can be seen from Fig. 4a graph that nanofiber modified specimens had a relatively worse load capacity. Delaminations in these specimens are considered as the reasons for the decrease in the load capacity [18]. The nanofiber modified specimens reached a load capacity similar to that of the pure $2 \mathrm{G}$ specimen's. $2 \mathrm{G} 1 \mathrm{~N}$ and $2 \mathrm{G} 3 \mathrm{~N}$ specimens performed similarly. The $4 \mathrm{G}$ specimen had the highest load carrying capacity among the specimen representatives due to having more glass fiber layers than others. Oscillations means damage occurred at the centers of the specimens [19]. Also, it should be noted that the vibrations that occur on the specimens when the impactor hit them can affect the force sensor. This condition can be observed in the graph.

The curves in Fig. 4b graph tried to form a closed curve. They failed to do so because some portion of the impact energy was used for the damage mechanisms that occurred on the specimens. The areas beneath those curves are equal to the deformation energies [10]. The displacement of the impactor started to take place with the impact and then the displacement retreated again after with four glass fiber layers, $2 \mathrm{G} 1 \mathrm{~N}$ represents nanofiber modified GFRP specimens with two glass fiber layers and one nanofiber mat and $2 \mathrm{G} 3 \mathrm{~N}$ represents nanofiber modified GFRP specimens with two glass fiber layers and three nanofiber mats.
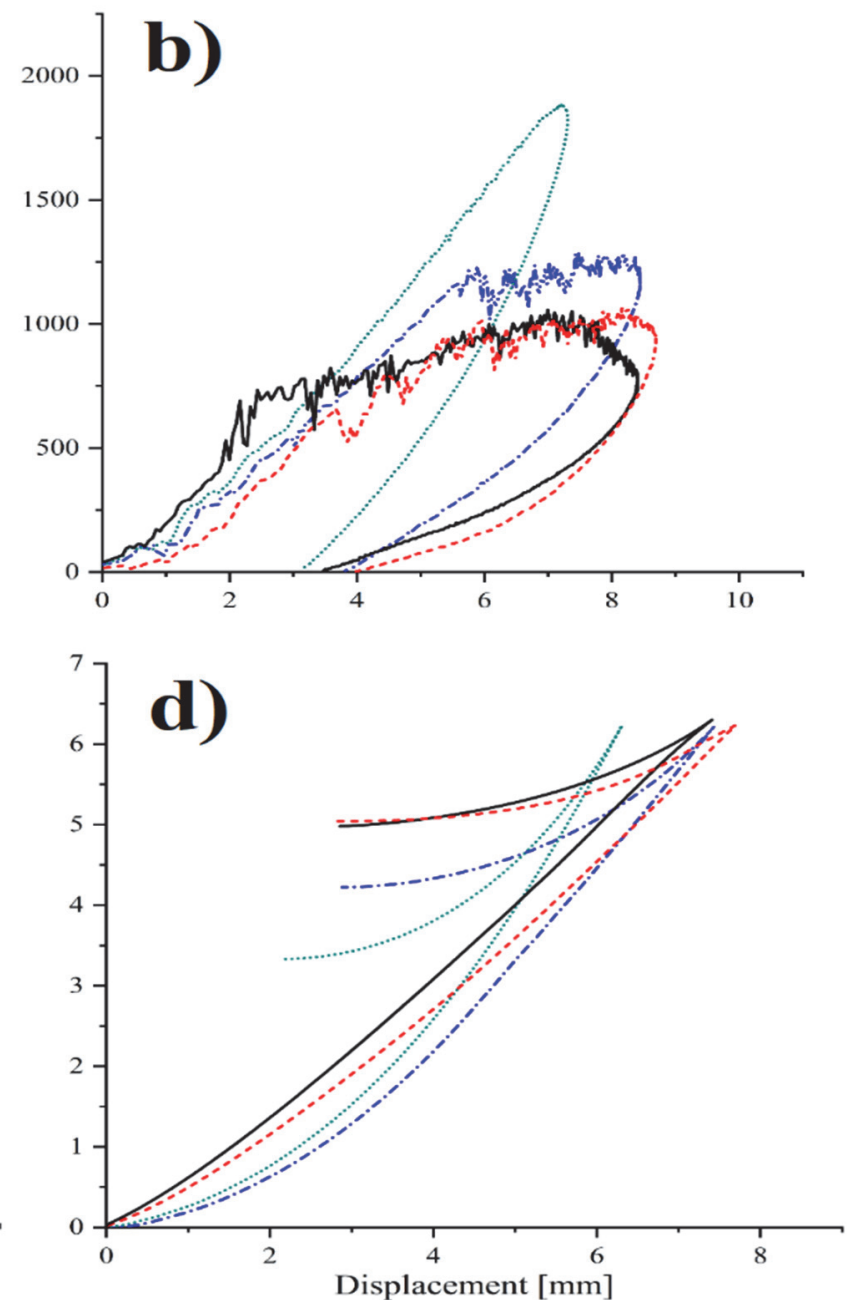

reaching a peak point. The $2 \mathrm{G}$ and the nanofiber modified specimens showed similar displacements with lower values than $4 \mathrm{G}$ specimen, due to limited damage.

Tab. 1 gives the max load values as well as the percentage changes between the specimens. The values of the delamination threshold (DLT) which is defined as the immediate drop in stiffness when damage occurs in laminates are provided in the table as well. Also there was not any prominent delamination in the $4 \mathrm{G}$ specimen as its curve shows a bell-shaped profile.

Table $1 \mathrm{Load}$ proportions and DLT values for the specimens

\begin{tabular}{|c|c|c|}
\hline Specimens & $2 \mathrm{G}$ & $4 \mathrm{G}$ \\
\hline Max load Capacity / N & $1289,28 \pm 31,2$ & $1886,9 \pm 19,57$ \\
\hline Change from $2 \mathrm{G} / \%$ & - & 46,35 \\
\hline Change from 4G / \% & $-31,67$ & - \\
\hline DLT / N & 1225,7 & - \\
\hline
\end{tabular}

In Fig. 4c, it is possible to observe the amount of energy absorbed in the specimens. The impact had a total of $6,3 \mathrm{~J}$ of kinetic energy and while the specimen absorbed a certain portion of the energy, the remaining kinetic 
energy was used to repulse the impactor. It is seen from the figure that there were repulsions for all of the specimens after the impactor hit the specimen. $2 \mathrm{G}$ and $4 \mathrm{G}$ specimens allowed for more recoil than the nanofiber modified ones. For nanofiber modified specimens, nanofibers helped the matrix stay together and improved absorption capabilities of the specimens and weaker rebound occurred. $2 \mathrm{G} 1 \mathrm{~N}$ and 2G3N specimens absorbed similar amounts of energy with 2G3N specimen performing only slightly better.

In Fig. 4d graph, it is seen that displacements were beginning to occur with the passage of energy to the specimens. The regression of the curves can give an impression on the specimen stiffness as it is mostly evident in the 4G specimen, which is the stiffest one among the specimens. The $2 \mathrm{G}$ and $2 \mathrm{G} 1 \mathrm{~N}$ specimens' regressions are similar while 2G3Nspecimens' regression is less. Energy proportions, percentage changes as well as impulses of the specimens, are given in Tab. 2.

From the impulse values, it can be said that the pure specimens had higher impulse values and it can be deduced that robust materials surely exhibit higher impulse values. Nanofiber modified specimens had similar impulse values, the $2 \mathrm{G} 3 \mathrm{~N}$ specimen being slightly lower. The increased energy absorption capacities of nanofiber modified specimens led to lower impulse values.

Table 2 Energy proportions for the specimens

\begin{tabular}{|c|c|c|c|}
\hline \multicolumn{4}{|c|}{ Table 2 Energy proportions for the specimens } \\
\hline Specimens & $2 \mathrm{G}$ & $4 \mathrm{G}$ & $2 \mathrm{G} 1 \mathrm{~N}$ \\
\hline Absorbed Energy / J & $4,29 \pm 0,005$ & $3,39 \pm 0,42$ & $4,97 \pm 0,026$ \\
\hline Change from 2G / \% & - & $-20,98$ & 15,9 \\
\hline Change from 4G / \% & 26,55 & - & 46,49 \\
\hline Rebound Energy / J & $2,01 \pm 0,005$ & $2,91 \pm 0,42$ & $1,33 \pm 0,026$ \\
\hline Change from 2G / \% & - & 44,77 & $-33,95$ \\
\hline Change from 4G / \% & $-30,93$ & - & $-54,32$ \\
\hline Impulses / Ns & 13,2 & 14,1 & $1,29 \pm 0,2$ \\
\hline
\end{tabular}

\subsection{Tensile Tests}

As was the case with the low velocity impact specimens, the specimens with optimum values were chosen as representatives. Stress-strain diagrams of the representatives were generated and comparisons were made.

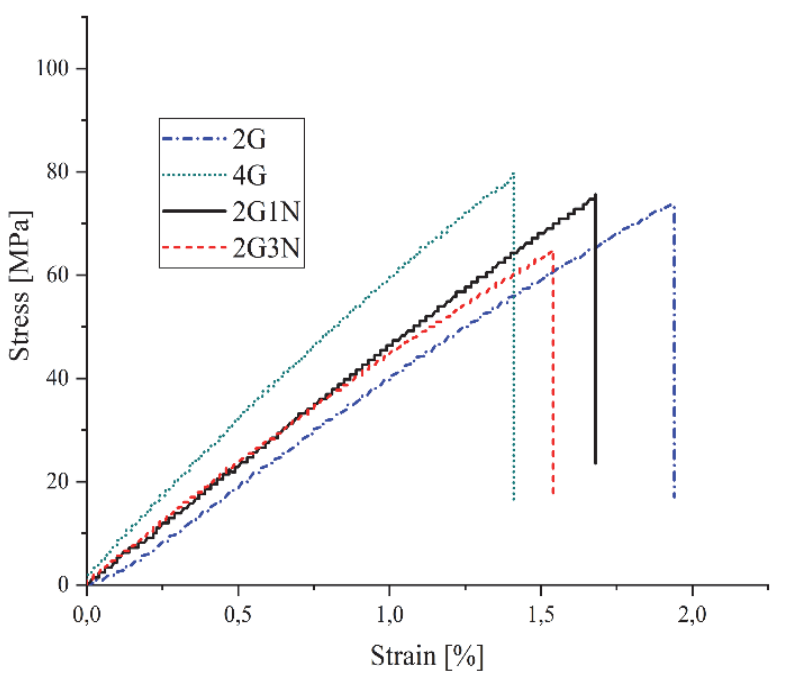

Figure 5 Stress-strain values of the specimens

Fig. 5 shows the stress-strain curves of the specimens. The profiles of curves are typical of laminated composites. From the graph, it can be seen that the pure specimens managed to reach better fracture stresses when compared to the nanofiber modified specimens. The effect of high rigidity, which pure materials have, is prominent here. The 2G3N specimen was damaged at lower stress values than $2 \mathrm{G} 1 \mathrm{~N}$ specimen. The general trend shows that the tensile strength decreased with the addition of nanofiber mats. As the slopes of the $2 \mathrm{G}, 2 \mathrm{G} 1 \mathrm{~N}$ and $2 \mathrm{G} 3 \mathrm{~N}$ are similar it can be said that the nanofiber mats did not have an impressive effect on the Young modulus of the specimens either. The poor performance of the $2 \mathrm{G} 3 \mathrm{~N}$ specimen is prominent. The reason is thought to be the increased disunities between the glass fiber and nanofiber mat as this specimen had three mats in a limited space. Still, it can be said that $2 \mathrm{G} 1 \mathrm{~N}$ specimen stayed closer to that of the $2 \mathrm{G}$ specimen in stress values. Nanofiber modified specimens had relatively less elongation; it is thought that their addition to the composites contributed to the specimens holding together. The mechanical properties of the specimens calculated by the tensile tests are given in Tab. 3. The young modules were generated from up to the point of $1 / 3$ of the max stress where elastic region point for GFRP composites is assumed [20].

Table 3 Tensile test results of the specimens

\begin{tabular}{|c|c|c|c|c|}
\hline Specimens & $\begin{array}{c}\text { Max. Load } \\
/ \mathrm{N}\end{array}$ & $\begin{array}{c}\text { Elongation / } \\
\%\end{array}$ & $\begin{array}{c}\text { Fracture / } \\
\mathrm{MPa}\end{array}$ & $\begin{array}{c}\text { Young Modulus } \\
/ \mathrm{GPa}\end{array}$ \\
\hline $2 \mathrm{G}$ & $\begin{array}{c}3825,6 \pm \\
417,9\end{array}$ & $1,94 \pm 0,19$ & $\begin{array}{c}73,57 \pm \\
8,04\end{array}$ & $3,95 \pm 0,04$ \\
\hline $2 \mathrm{G}$ & $\begin{array}{c}4149,6 \pm \\
652,1\end{array}$ & $1,41 \pm 0,33$ & $\begin{array}{c}79,80 \pm \\
12,54\end{array}$ & $5,46 \pm 0,49$ \\
\hline $2 \mathrm{G} 1 \mathrm{~N}$ & $\begin{array}{c}3932,8 \pm \\
466,9\end{array}$ & $1,68 \pm 0,39$ & $\begin{array}{c}75,63 \pm \\
8,93\end{array}$ & $4,47 \pm 0,55$ \\
\hline $2 \mathrm{G} 3 \mathrm{~N}$ & $\begin{array}{c}3384,7 \pm \\
423,5\end{array}$ & $1,54 \pm 0,4$ & $\begin{array}{c}65,09 \pm \\
8,14\end{array}$ & $4,1 \pm 0,63$ \\
\hline
\end{tabular}

Fig. 6 shows the SEM images of the damaged surfaces of the specimens subjected to tensile tests. Matrix cracks, fiber pull-outs and fiber breaks are prominent damage mechanisms in all of the specimens. The remnants of the matrix on the glass fibers could be seen. Also, much debris was present, as expected. In the $2 \mathrm{G}$ specimen significant debonding, crack propagation and delamination damages could be observed. In comparison, there was limited debonding in the $4 \mathrm{G}$ specimen and matrix rupture was visible. With the addition of nanofiber mats, stresses that accumulated in the matrix near those mats could be observed. Those stresses effectively made a drop in the load capabilities of the specimens. The $2 \mathrm{G} 3 \mathrm{~N}$ specimen had significantly bigger matrix cracks compared to those of $2 \mathrm{G} 1 \mathrm{~N}$ specimens. Slits were also visible in the nanofiber mats; it is assumed that the stresses progressed into the mats as well. 


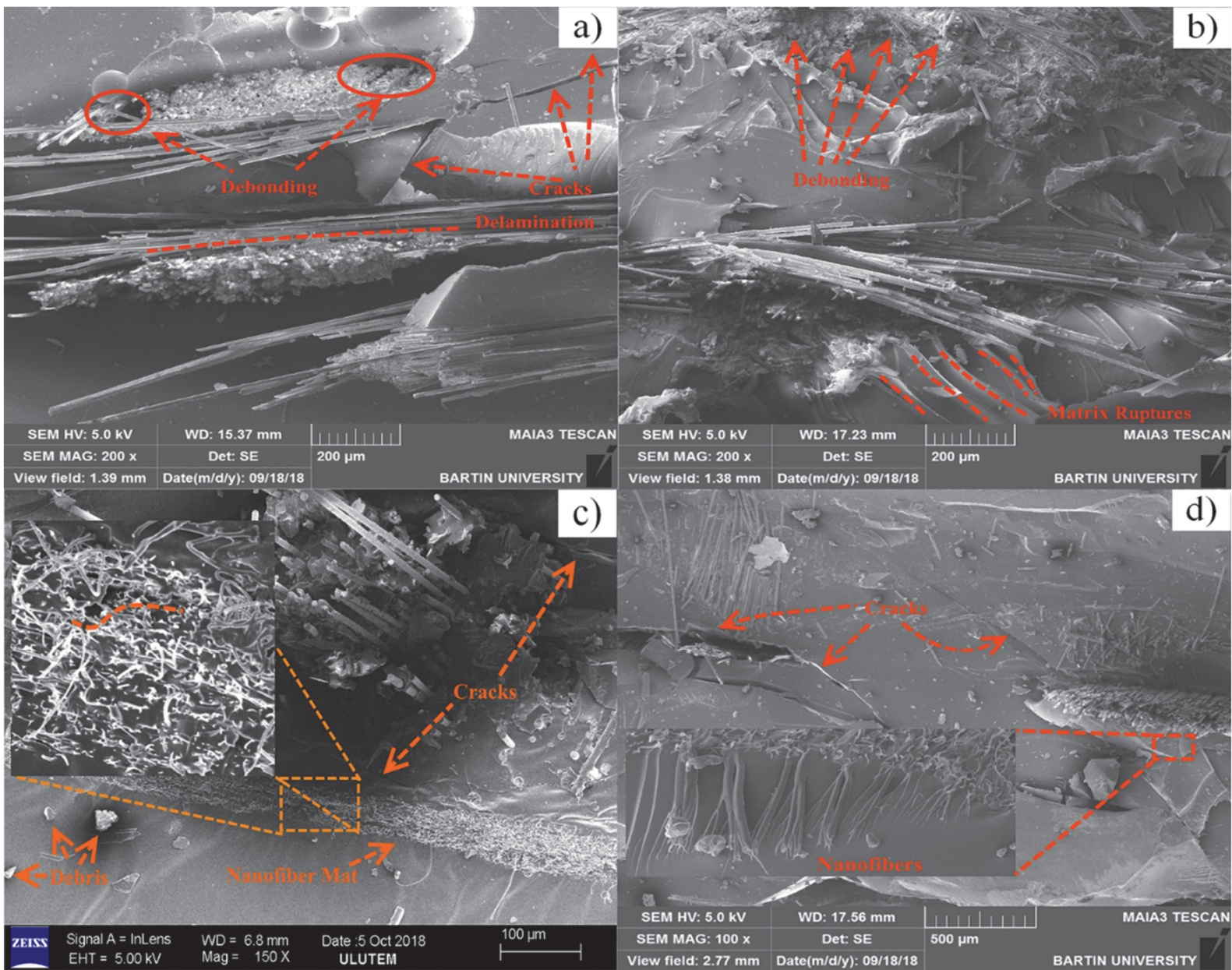

Figure 6 SEM images of the tensile test specimens: a) 2G; b) 4G; c) $2 \mathrm{G} 1 \mathrm{~N}$; d) $2 \mathrm{G} 3 \mathrm{~N}$

\section{CONCLUSION}

In this study, the effects of the addition of nylon 6,6 nanofiber mats obtained by electrospinning method to GFRP composites were investigated. The nanofiber mats generated by the electrospinning method were interleaved into two glass fiber layered GFRP laminated composite, in one and three mats. Also, pure composites with two and four glass fiber were manufactured as well. Low velocity and tensile tests were used as the test methods.

The low velocity impact tests showed that increasing the number of glass fiber layers increased the strength of the specimens as expected. But nylon 6,6 nanofiber mats have caused reductions in load capacity. Delamination and matrix damage were prominent damage mechanisms. Still, nanofibers helped the damaged matrix to hold together. Adding more than one nanofiber mat did not cause any significant improvement as the load and energy absorption values of specimens modified with one and three mats were quite similar to each other. The nanofiber modified specimens absorbed approximately $16,5 \%$ more energy than the two-layered pure specimens and approximately $45 \%$ more energy than the four-layered specimens.

From tensile tests it seems that increasing the number of glass fiber layer promoted stiffness to increase and displacement to decrease. But increasing the number of nanofiber mats caused the tensile strength to decrease. Also the results showed that interleaving three nanofiber mats did not cause a significant improvement when compared to specimens modified with one nanofiber mat. Another point is that nanofiber mats did not cause any significant effect on the Young modulus of the specimens they are added into, as compared to pure two glass fiber reinforced epoxy matrix specimens.

\section{REFERENCES}

[1] Zucchelli, A., Focarete, M. L., Gualandi, C., \& Ramakrishna, S. (2011). Electrospun nanofibers for enhancing structural performance of composite materials. Polymers for Advanced Technologies, 22(3), 339-349. https://doi.org/10.1002/pat.1837

[2] Saghafi, H., Palazzetti, R., Zucchelli, A., \& Minak, G. (2015). Influence of electrospun nanofibers on the interlaminar properties of unidirectional epoxy resin/glass fiber composite laminates. Journal of Reinforced Plastics and Composites, 34(11), 907-914. https://doi.org/10.1177/0731684415584635

[3] Akangah, P., Lingaiah, S., \& Shivakumar, K. (2010). Effect of Nylon-66 nano-fiber interleaving on impact damage resistance of epoxy/carbon fiber composite laminates. Composite Structures, 92(6), 1432-1439. https://doi.org/10.1016/j.compstruct.2009.11.009

[4] Bhardwaj, N., \& Kundu, S. C. (2010). Electrospinning: a fascinating fiber fabrication technique. Biotechnology advances, 28(3), 325-347. https://doi.org/10.1016/j.biotechadv.2010.01.004

[5] Huang, Z. M., Zhang, Y. Z., Kotaki, M., \& Ramakrishna, S. (2003). A review on polymer nanofibers by electrospinning and their applications in nanocomposites. Composites science and technology, 63(15), 2223-2253. https://doi.org/10.1016/S0266-3538(03)00178-7 
[6] Behler, K., Havel, M., \& Gogotsi, Y. (2007). New solvent for polyamides and its application to the electrospinning of polyamides 11 and 12. Polymer, 48(22), 6617-6621. https://doi.org/10.1016/j.polymer.2007.08.058

[7] Zussman, E., Burman, M., Yarin, A. L., Khalfin, R., \& Cohen, Y. (2006). Tensile deformation of electrospun nylon6, 6 nanofibers. Journal of Polymer Science Part B: Polymer Physics, 44(10), 1482-1489. https://doi.org/10.1002/polb.20803

[8] Yang, B., Kozey, V., Adanur, S., \& Kumar, S. (2000). Bending, compression, and shear behavior of woven glass fiber-epoxy composites. Composites Part B: Engineering, 31(8), 715-721. https://doi.org/10.1016/S1359-8368(99)00052-9

[9] Aslan, Z., Karakuzu, R., \& Okutan, B. (2003). The response of laminated composite plates under low-velocity impact loading. Composite structures, 59(1), 119-127. https://doi.org/10.1016/S0263-8223(02)00185-X

[10] Belingardi, G., \& Vadori, R. (2002). Low velocity impact tests of laminate glass-fiber-epoxy matrix composite material plates. International Journal of Impact Engineering, 27(2), 213-229. https://doi.org/10.1016/S0734-743X(01)00040-9

[11] Liu, L., Huang, Z. M., He, C. L., \& Han, X. J. (2006). Mechanical performance of laminated composites incorporated with nanofibrous membranes. Materials Science and Engineering: A, 435, 309-317. https://doi.org/10.1016/j.msea.2006.07.064

[12] Kelkar, A. D., Mohan, R., Bolick, R., \& Shendokar, S. (2010). Effect of nanoparticles and nanofibers on Mode I fracture toughness of fiber glass reinforced polymeric matrix composites. Materials Science and Engineering: B, 168(13), 85-89. https://doi.org/10.1016/j.mseb.2010.01.015

[13] Yademellat, H., Nikbakht, A., Saghafi, H., \& Sadighi, M. (2018). Experimental and numerical investigation of low velocity impact on electrospun nanofiber modified composite laminates. Composite Structures, 200, 507-514. https://doi.org/10.1016/j.compstruct.2018.05.146

[14] Brugo, T., Minak, G., Zucchelli, A., Yan, X. T., Belcari, J., Saghafi, H., \& Palazzetti, R. (2017). Study on Mode I fatigue behaviour of Nylon 6, 6 nanoreinforced CFRP laminates. Composite Structures, 164, 51-57. https://doi.org/10.1016/j.compstruct.2016.12.070

[15] Beylergil, B., Tanoğlu, M., \& Aktaş, E. (2018). Effect of polyamide-6, 6 (PA 66) nonwoven veils on the mechanical performance of carbon fiber/epoxy composites. Composite Structures, 194, 21-35. https://doi.org/10.1016/j.compstruct.2018.03.097

[16] Nylon 6/6 pellets, (2017). Retrieved from http://www.sigmaaldrich.com/catalog/product/aldrich/4291 71

[17] Epoxy Systems / Lamination Epoxy, HEXION MGS L160 System, (2010). Retrieved from http://www.dostkimya.com/en/product-browser/laminationepoxy-hexion-mgs-1160-system/51

[18] Yapici, A. \& Metin, M. (2009). Effect of low-speed impact damage on the buckling properties of E-glass/epoxy laminates. Mechanics of Composite Materials, 45(6), 577582. https://doi.org/10.1007/s11029-010-9114-5

[19] Ulus, H., Üstün, T., Şahin, Ö. S., Karabulut, S. E., Eskizeybek, V., \& Avc1, A. (2016). Low-velocity impact behavior of carbon fiber/epoxy multiscale hybrid nanocomposites reinforced with multiwalled carbon nanotubes and boron nitride nanoplates. Journal of Composite Materials, 50(6), 761-770. https://doi.org/10.1177/0021998315580835

[20] Štefić, T., Jurić, A., \& Marović, P. (2011). Determination of modulus of elasticity for glass fibre reinforced polymers. Tehnički vjesnik, 18(1), 69-72.

\section{Contact information:}

Murat YILDIZ, R. A

(Corresponding author)

Mechanical Eng. Dep.,

Iskenderun Technical University,

Hatay, TURKEY

E-mail: murat.yildiz@iste.edu.tr

Ahmet YAPICI, Prof. Dr.

Mechanical Eng. Dep.

Iskenderun Technical University, Hatay, TURKEY

E-mail: ahmet.yapici@iste.edu.tr

Vildan ÖZKAN, PhD

Petroleum and Natural Gas Eng. Dep. Iskenderun Technical University, Hatay, TURKEY

E-mail: vildan.ozkan@iste.edu.tr

Ömer Sinan ŞAHiN, Prof. Dr. Mechanical Eng. Dep., Konya Technical University, Konya, TURKEY

E-mail: ossahin@ktun.edu.tr 